\title{
Tobacco use among adolescents in Qatar: Findings from Global Youth Tobacco Surveys 2004-2013
}

\author{
Ayman Al-Dahshan', Mohamad El Zoghbi', Mohamad Abdul Halim Chehab', Sarah Naja', Nagah Abdel Aziz Selim",
}

\begin{abstract}
INTRODUCTION Tobacco use has become a global health concern. Almost a third of the adolescents of the Eastern Mediterranean Region (EMR) have reported tobacco use and the percentage is expected to rise in the future, making tobacco consumption a main public health issue among students, 13-15 years old, in the region's countries. We aimed to conduct an analysis of the previous Global Youth Tobacco Surveys (GYTS) in Qatar to detect any significant changes that might inform decision makers on planning policies and interventions accordingly.

METHODS This study presents a retrospective data analysis, based on three GYTS conducted in Qatar during 2004, 2007, and 2013. All analyses were weighted to account for the complex survey design and for differential non-response at school, class and student levels, with the exception of the analysis of sociodemographic characteristics. The differences between the proportions were tested by Pearson's chi-squared test. Data were analyzed using the statistical software SPSS (Statistical Package for Social Sciences), version 21.0 (Chicago, IL). A p-value $<0.05$ was considered to be significant.

RESULTS There was an overall increase in the prevalence of smoking, the accessibility, and the availability of cigarettes. Additionally, the percentage of participants who desired to stop smoking decreased between 2004 and 2013, while that of students who reported 'exposure to free tobacco promotion' was highest in 2013.

CONCLUSIONS Despite the effort made by the local authorities in Qatar to reverse the spread or limit the growing tobacco epidemic, there is a need for multidisciplinary interventions through tobacco prevention and control programs targeting youths.
\end{abstract}

ABBREVIATIONS EMR: Eastern Mediterranean Region, GYTS: Global Youth Tobacco Survey, GCC: Gulf Cooperation Council

\section{AFFILIATION}

1 Community Medicine Residency

Program, Hamad Medical

Corporation, Doha, Qatar

2 Quality Management

Department, Primary Health Care

Corporation, Doha, Qatar

3 Public Health and Preventive

Medicine, Faculty of Medicine,

Cairo University, Cairo, Egypt

4 Community Medicine Residency

Program, Primary Health Care

Corporation, Doha, Qatar

\section{CORRESPONDENCE TO}

Mohamad El Zoghbi. Quality

Management Department Primary

Health Care Corporation, PO Box

26555, Doha, Qatar.

E-mail: zoghbi2001@hotmail.com

KEYWORDS

adolescent, tobacco use, survey,

smoking, Qatar

Received: 12 October 2018

Revised: 1 February 2019

Accepted: 28 February 2019

\section{INTRODUCTION}

Tobacco use has become a global health concern and afflicts developed as well as developing countries ${ }^{1}$. Today, the majority of the world's one billion tobaccoconsumers are located in developing countries ${ }^{2}$. Moreover, most of the world's current smokers initiated the habit during their adolescence. Similarly, the duration of tobacco use has been inversely associated with the age of initiation ${ }^{3}$. Globally, the number of adolescent boys and girls, who smoke cigarettes, has been estimated at 25 million and 13 million, respectively $y^{4}$. This deadly habit has become a pandemic responsible for six million deaths annually ${ }^{5}$. In the EMR, the prevalence of tobacco use is underestimated due to several factors, including lack of data from some countries, underreporting by females, and the presence of unaccounted methods of tobacco consumption (e.g. water-pipe $)^{6}$. In addition, a report on the trend in adolescent tobacco use in EMR countries between 1999 and 2007 revealed tobacco consumption as a main public health issue among students 13-15 years old ${ }^{7}$. Moreover, almost a third of the region's adolescents have reported tobacco use and the percentage is expected to rise in the future ${ }^{8}$. 
Earlier research has shown that tobacco use among relatives, peer pressure, and parent-child relationships play an important role in smoking behavior among adolescents ${ }^{9}$. On the other hand, several strategies have proven effective in preventing the spread of tobacco use among adolescents, such as school-based interventions as well as targeted primary health care services $^{10,11}$.

The Global Youth Tobacco Survey (GYTS) was established in 1998 to monitor tobacco consumption among the youth as well as guide the implementation and evaluation of prevention and control programs ${ }^{12}$. A separate review, involving the GYTS conducted in the Gulf Cooperation Council (GCG) countries, found a high prevalence of tobacco consumption, considerable exposure $(30 \%)$ to passive smoke in public areas, and an increased vulnerability of nonsmokers to start smoking in the next academic year ${ }^{13}$.

Qatar developed its first tobacco-related legislation in 2002 and signed the World Health Organization Framework Convention on Tobacco Control (WHO FCTC) in $2004^{14}$. However, the country was one of the nations with the highest prevalence $(30.2 \%)$ of tobacco use among adolescents based on a study of the Global Schoolbased Student Health Surveys from 68 low- and middle-income countries ${ }^{15}$. Nevertheless, Qatar's constitution encompasses multiple well-established laws and decrees that govern the importation, advertising, vending, and use of tobacco and its derivatives ${ }^{16}$. As of 2018, the State of Qatar had participated three times in the GYTS in 2004, 2007 and 2013.

Thus, we aimed to analyze the datasets of the three GYTS to study the changes in tobacco use among adolescents in Qatar that might inform decision makers on planning policies as well as interventions accordingly.

\section{METHODS}

\section{Study design, sampling and data collection}

The current paper presents a retrospective data analysis using cross-sectional surveys based on the three GYTS, which are self-administered, anonymous and voluntary surveys ${ }^{17}$. In Qatar, the Ministry of Public Health and the Ministry of Education conducted the GYTS during 2004, 2007 and 2013. The surveys aimed to evaluate the smoking habits and beliefs among Qatar's Middle school students aged between 13 and 15 years.

The samples taken were nationally representative. The sampling frame encompassed all schools that include the grades associated with the ages between 13 and 15 years. The surveys were carried out among a sample of the target population using a two-stage cluster sample design. During the first stage, schools were selected proportionally according to enrollment size. In the second stage, classes were randomly selected within participating schools and all students present in the selected classes on the day of the survey administration were eligible to participate. Therefore, the samples taken were nationally representative and had a high response rate. The first survey conducted in 2004 was among grades eight to ten, while the following surveys of 2007 and 2013 were among grades seven to nine $\mathrm{e}^{12,18,19}$

The three datasets, including the questions and results, are available through the Centers for Disease Control and Prevention (CDC) website ${ }^{17}$.

\section{Statistical analysis}

The three versions of the GYTS that were used to collect data in 2004, 2007 and 2013 included a different number of questions $(56,71$ and 78 respectively). The three surveys had 25 similar questions related to the study objective (in addition to the three sociodemographic questions), while the other questions were different. In addition, the answers to some questions included in the current study were not exactly the same, and therefore we recoded them.

Our analyses exclusively included students aged between 13 and 15 years. In each data set and for each student record, a weighting factor was applied for non-response adjustment (by school, class and student) and for the variation in the probability of selecting a school and a class. The final adjustment included calculating the average weight by sex and grade for each sample site. The weighting factor calculation was described previously in detail ${ }^{12,18-20}$.

We used the weighting factor to conduct our statistical analyses, with the exception of the analysis of the sociodemographic characteristics. The differences between the proportions were tested by Pearson's chi-squared test. The statistical software SPSS (Statistical Package for Social Sciences), 
version 21.0 (Chicago, IL) was used to analyze the data. A p-value less than 0.05 was considered statistically significant.

\section{RESULTS}

Overall, 2229, 943 and 1716 students aged between 13 and 15 years old participated in the 2004, 2007 and 2013 surveys, respectively (Table 1).

The weighted percentage (24.8\%) of ever cigarette smokers among participants of the 2013 survey is significantly higher than that observed in the 2004 and 2007 surveys $(22.4 \%$ and $20.7 \%$, respectively; $\mathrm{p}<0.001)$. The percentage of current smokers among the 2013 survey participants $(9.8 \% ; 7.1 \%$ non-frequent smokers and $2.7 \%$ frequent smokers) is significantly higher than that observed in 2004 (6.4\%; $4.5 \%$ non-frequent smokers and $1.9 \%$ frequent smokers) and in 2007 (6.5\%; 5.8\% non-frequent smokers and $0.7 \%$ frequent smokers). Regarding the signs of smoking dependence, the weighted percentages of those who reported to have a cigarette or feel like having a cigarette first thing in the morning' among the current smokers decreased gradually from $38.9 \%$ in 2004 , to $35.8 \%$ in 2007 , and $25.3 \%$ in $2013(\mathrm{p}<0.001)$. Moreover, the percentage of those
Table 1. Main characteristics of the Surveys' participants

$\begin{array}{lcccc} & 2001 & 2007 & 2013 & \\ & (N 229) & (N-9) & (N-1716) & \\ \text { Gender } & & & & \\ \text { Boys } & 1009(45.6) & 362(40.7) & 893(52.5) & <0.001 \\ \text { Girls } & 1203(54.4) & 527(59.3) & 807(47.5) & \\ \text { Age (Years) } & & & & \\ 13 & 638(28.6) & 382(40.5) & 667(38.9) & \\ 14 & 885(39.7) & 329(34.9) & 639(37.2) & <0.001 \\ 15 & 706(31.7) & 232(24.6) & 410(23.9) & \\ \text { School } & & & & \\ \text { Grade level } & & & & \\ 7 & 0(0.0) & 327(36.7) & 438(26.0) & \\ 8 & 921(41.7) & 273(30.6) & 603(35.8) & \text { NA } \\ 9 & 787(35.7) & 292(32.7) & 645(38.3) & \\ 10 & 498(22.6) & 0(0.0) & 0(0.0) & \end{array}$

a Pearson's chi-squared test. NA: not appropriate.

smoking other products declined by almost half in $2013(7.0 \%)$ compared to that in $2004(13.7 \%)$ and 2007 (12.8\%; p<0.001) (Table 2).

Among smokers in the three surveys, the weighted percentage of participants who desired to stop smoking was significantly higher during 2004 and

Table 2. Cigarette smoking details among the participants of the three Surveys (2004, 2007 and 2013)

\begin{tabular}{|c|c|c|c|c|}
\hline & $\begin{array}{c}2004 \\
n_{w}\left(\%_{w}\right)\end{array}$ & $\begin{array}{c}2007 \\
n_{n}\left(\%_{n}\right)\end{array}$ & $\begin{array}{c}2013 \\
n_{w}\left(\%_{w}\right)\end{array}$ & $p^{a}$ \\
\hline \multicolumn{5}{|c|}{ Ever cigarette smokers } \\
\hline Yes & $2774(22.4)$ & $1622(20.7)$ & $4035(24.8)$ & $<0.001$ \\
\hline \multicolumn{5}{|c|}{ Current cigarette smokers } \\
\hline Current smokers & $775(6.4)$ & $509(6.5)$ & $1576(9.8)$ & $<0.001$ \\
\hline \multicolumn{5}{|c|}{ Age (years) at cigarette smoking initiation ${ }^{b}$} \\
\hline$<12$ & $1012(47.4)$ & $556(47.0)$ & $1708(47.8)$ & \multirow{2}{*}{0.884} \\
\hline$\geq 12$ & $1121(52.6)$ & $628(53.0)$ & $1867(52.2)$ & \\
\hline \multicolumn{5}{|c|}{ Frequency of cigarette smoking ${ }^{b}$} \\
\hline Non-frequent ${ }^{c}$ & $543(70.1)$ & $454(89.2)$ & $1143(72.5)$ & \multirow{2}{*}{$<0.001$} \\
\hline Frequent $^{d}$ & 232 (29.9) & $55(10.8)$ & $433(27.5)$ & \\
\hline \multicolumn{5}{|c|}{$\begin{array}{l}\text { Number of cigarettes smoked per day during the } \\
\text { past } 30 \text { days }^{\mathrm{b}}\end{array}$} \\
\hline $0-10$ & 721 (83.4) & 532 (96.9) & $1487(88.9)$ & \multirow{2}{*}{$<0.001$} \\
\hline$>10$ & $144(16.6)$ & $17(3.1)$ & $186(11.1)$ & \\
\hline \multicolumn{5}{|c|}{$\begin{array}{l}\text { Have a cigarette or feel like having a cigarette } \\
\text { first thing in the morning }\end{array}$} \\
\hline Yes & 222 (38.9) & $116(35.8)$ & $1032(25.3)$ & $<0.001$ \\
\hline \multicolumn{5}{|c|}{ Current smokers of other products } \\
\hline Yes & $1678(13.7)$ & $1015(12.8)$ & $1129(7.0)$ & $<0.001$ \\
\hline
\end{tabular}


2007 (53.9\% and 59.6\%, respectively) than in 2013 (43.9\%; p<0.001) (Table 3).

The weighted percentage of participants who agreed with 'Banning smoking in enclosed public places' declined from a majority of $84.8 \%$ and $81.3 \%$ in 2004 and 2007, respectively, to less than half $(48.3 \%)$ in 2013 . Regarding passive smoking, the weighted percentage of participants exposed to secondhand smoke decreased from almost a third $(30.2 \%)$ in 2004 to a quarter $(24.2 \%)$ in 2013 , despite a rise of $35.7 \%$ in $2007(\mathrm{p}<0.001)$ (Table 4).

Among those who attended sports or community events, less than half (45.2\%) reported 'awareness of anti-tobacco messages' in 2013, which represents

Table 3. Accessibility and availability of cigarettes and smoking cessation details among the participants of the three Surveys (2004, 2007 and 2013)

\begin{tabular}{|c|c|c|c|c|}
\hline & $\begin{array}{l}2001 \\
n_{w}\left(\%_{w}\right)\end{array}$ & $\begin{array}{l}2007 \\
n_{1}\left(\%_{n}\right)\end{array}$ & $\begin{array}{c}2013 \\
n_{w}\left(\%_{w}\right)\end{array}$ & $p^{a}$ \\
\hline \multicolumn{5}{|l|}{ Source of cigarettes ${ }^{b}$} \\
\hline Store, shop, street vendor, cafeteria or kiosk & $456(40.2)$ & $196(30.0)$ & $1664(66.1)$ & \multirow{3}{*}{$<0.001$} \\
\hline Someone else & $314(27.7)$ & $235(36.0)$ & 437 (17.3) & \\
\hline Other & $365(32.2)$ & $222(34.0)$ & $418(16.6)$ & \\
\hline \multicolumn{5}{|l|}{ Minors' access to purchasing cigarettes ${ }^{b}$} \\
\hline $\begin{array}{l}\text { Yes, someone refused to sell me cigarettes because } \\
\text { of my age }\end{array}$ & $446(45.5)$ & $277(42.5)$ & $990(50.1)$ & \multirow[t]{2}{*}{0.001} \\
\hline No, my age did not keep me from buying cigarettes & $535(54.5)$ & $374(57.5)$ & 988 (49.9) & \\
\hline \multicolumn{5}{|l|}{ Desire to stop smoking ${ }^{b}$} \\
\hline Yes & $523(53.9)$ & $434(59.6)$ & $845(43.9)$ & $<0.001$ \\
\hline \multicolumn{5}{|l|}{ Attempt to stop smoking in the past 12 months $^{b}$} \\
\hline Yes & $580(54.4)$ & $314(53.6)$ & 1206 (56.9) & 0.212 \\
\hline \multicolumn{5}{|l|}{ Ability to stop smoking ${ }^{b}$} \\
\hline Yes & $896(69.5)$ & $575(78.2)$ & $1434(66.6)$ & $<0.001$ \\
\hline \multicolumn{5}{|l|}{ Received help to stop smoking ${ }^{b}$} \\
\hline Yes & $1766(76.9)$ & 1134 (86.2) & $2440(70.5)$ & $<0.001$ \\
\hline
\end{tabular}

Table 4. Knowledge and attitudes related to cigarette smoking and secondhand smoking among the participants of the three Surveys (2004, 2007 and 2013)

\begin{tabular}{|c|c|c|c|c|}
\hline & $\begin{array}{c}2001 \\
n_{w}\left(\%_{w}\right)\end{array}$ & $\begin{array}{c}2007 \\
n_{w}\left(\%_{w}\right)\end{array}$ & $\begin{array}{c}2013 \\
n_{w}\left(\%_{w}\right)\end{array}$ & $p^{a}$ \\
\hline \multicolumn{5}{|c|}{ Beliefs about the addictiveness of smoking } \\
\hline Yes & $6973(56.6)$ & $4486(55.9)$ & $9163(56.3)$ & 0.582 \\
\hline \multicolumn{5}{|c|}{ Beliefs about the dangers of secondhand smoke } \\
\hline Yes & $10985(88.7)$ & $6596(82.1)$ & $12645(76.9)$ & $<0.001$ \\
\hline \multicolumn{5}{|c|}{$\begin{array}{l}\text { Belief that smoking helps people feel } \\
\text { comfortable at social gatherings }\end{array}$} \\
\hline More comfortable & $2145(17.5)$ & $1322(16.7)$ & $3403(22.0)$ & \multirow{3}{*}{$<0.001$} \\
\hline Less comfortable & $5734(46.8)$ & $5332(67.5)$ & $5974(38.7)$ & \\
\hline No difference from non-smokers & $4368(35.7)$ & $1240(15.7)$ & $6063(39.3)$ & \\
\hline \multicolumn{5}{|c|}{ Agree with banning smoking in public places } \\
\hline Yes & 10499 (84.8) & $6335(81.3)$ & 7976 (48.3) & $<0.001$ \\
\hline \multicolumn{5}{|c|}{ Exposure to secondhand smoke at home } \\
\hline Yes & $3750(30.2)$ & $2848(35.7)$ & $4044(24.2)$ & $<0.001$ \\
\hline \multicolumn{5}{|c|}{$\begin{array}{l}\text { Exposure to secondhand smoke in enclosed } \\
\text { public places }\end{array}$} \\
\hline Yes & $5824(46.8)$ & 3688 (45.9) & 7981 (47.9) & 0.010 \\
\hline
\end{tabular}

$\mathrm{n}_{\mathrm{w}}$ : weighted frequency.; $\%_{\mathrm{w}}$ : weighted percentage. a Pearson's chi-squared test. 
Table 5. Tthe awareness of anti-tobacco and pro-tobacco messages among the participants of the three Surveys (2004, 2007 and 2013)

\begin{tabular}{|c|c|c|c|c|}
\hline & $\begin{array}{c}2001 \\
n_{w}\left(o_{o_{w}}\right)\end{array}$ & $\begin{array}{c}2007 \\
n_{w}\left(o_{w_{w}}\right)\end{array}$ & $\begin{array}{c}2013 \\
n_{w}\left(\%_{w}\right)\end{array}$ & $p^{a}$ \\
\hline \multicolumn{5}{|c|}{ Awareness of anti-tobacco messages in the media } \\
\hline Yes & $7984(64.4)$ & $5328(68.4)$ & $8347(52.9)$ & $<0.001$ \\
\hline \multicolumn{5}{|c|}{$\begin{array}{l}\text { Awareness of anti-tobacco messages at sporting } \\
\text { or community events }{ }^{b}\end{array}$} \\
\hline Yes & $8549(88.1)$ & $5741(90.1)$ & $4131(45.2)$ & $<0.001$ \\
\hline \multicolumn{5}{|c|}{ Learning about dangers of tobacco use at school } \\
\hline Yes & $2303(18.7)$ & $3928(49.7)$ & $7507(47.2)$ & \multirow{3}{*}{$<0.001$} \\
\hline No & $7470(60.5)$ & $2257(28.6)$ & $6843(43.0)$ & \\
\hline I don't know & $2570(20.8)$ & $1715(21.7)$ & $1548(9.7)$ & \\
\hline \multicolumn{5}{|c|}{$\begin{array}{l}\text { Awareness of tobacco use on television, videos, } \\
\text { or movies }{ }^{c}\end{array}$} \\
\hline Yes & $11118(95.4)$ & $7123(94.5)$ & $8455(63.5)$ & $<0.001$ \\
\hline \multicolumn{5}{|c|}{ Ownership of an object with a tobacco brand logo } \\
\hline Yes & $1239(10.2)$ & $1241(16.8)$ & $2453(16.2)$ & $<0.001$ \\
\hline \multicolumn{5}{|c|}{ Exposure to free tobacco promotion } \\
\hline Yes & $1082(8.9)$ & $605(8.0)$ & 1712 (11.0) & $<0.001$ \\
\hline
\end{tabular}

$\mathrm{n}_{\mathrm{w}}$ : weighted frequency.; $\%$ : weighted percentage. a Pearson's chi-squared test. b Excluding: "I did not go to sports events, fairs, concerts, or community events, or social gatherings in the past 30 days". c Excluding: "I did not watch TV, videos, or movies in the past 30 days".

a significant drop from the percentages in the 2004 and 2007 surveys $(88.1 \%$ and $90.1 \%$, respectively; $\mathrm{p}<0.001)$. Further, the lowest percentage of participants who reported 'learning about dangers of tobacco use at school' was observed in 2004 (18.7\%), compared to those in $2007(49.7 \%)$ and 2013 $(47.2 \%)(\mathrm{p}<0.001)($ Table 5$)$.

\section{DISCUSSION}

To our knowledge, this is the first study comparing the findings of the three GYTS conducted in the State of Qatar during the years of 2004, 2007 and 2013. The main findings in this paper demonstrate that between 2004 and 2013, there was an overall increase in the prevalence of smoking, a decline in the role of media in promoting pro-tobacco and anti-tobacco messages, a drop in secondhand smoke exposure at home, a rise in smoking prevalence in enclosed public spaces, and a decrease in smoking cessation. The findings were unexpected because Qatar's National Health Strategy (2011-2016) had adopted a project (Project 3.3), which draws on the WHO MPOWER themes. The MPOWER is a set of six components for tobacco control and include the following: Monitor tobacco use and prevention policies; Protect people from tobacco smoke; Offer help to quit tobacco use;
Warn about the dangers of tobacco; Enforce bans on tobacco advertising, promotion and sponsorship; and Raise taxes on tobacco. Thus, Project 3.3 'Tobacco Cessation' aimed to decrease the current consumption of tobacco by $3 \%$ through the enhancement of tobacco cessation and awareness strategies, such as increasing the accessibility to smoking cessation clinics and reviewing national laws to increase taxation on tobacco products. Moreover, the project aims at strengthening the prevention of smoking among young people and expanding the smoke-free environments ${ }^{21,22}$.

The unforeseen trend of smoking among school going adolescents in Qatar could be linked to several factors seen in our analysis: 1) a decreased desire among adolescents to quit smoking, 2) the deficiency of smoking cessation services offered to adolescents in the country, and 3) an unwanted yet increased accessibility to tobacco products for adolescents, especially in the shops and cafeterias that offer tobacco. Although there is an increased resistance among merchants regarding not selling tobacco to minors, the prevalence of smokers in that age group was not affected significantly.

The increased proportion (by $2 \%$ ) of smokers among the adolescent age group in Qatar from 2004 
to 2013 is less than the dramatic increase seen in other countries such as Timor-Leste in Portugal, where the percentage of minor smokers (aged 1315 years) rose by $19 \%$ between 2006 and $2009^{23}$. On the other hand, the GYTS in Panama showed a decrease in the percentage of current cigarette smoking, among those aged 13-15 years, from $13.2 \%$ to $4.3 \%$ between 2002 and $2008^{24}$. As for GCC countries, a limited number of studies evaluated the trend of youth smoking over time. Similarly, the three GYTS conducted in Saudi Arabia revealed an unspecific pattern in smoking over the years, where the prevalence of ever smokers (aged 15-18 years) was $34.5 \%$ in 2001 that decreased to $27 \%$ in 2007 but then suddenly increased to $42.8 \%$ in $2010^{25}$. On the other hand, a cross-sectional study conducted in the United Arab Emirates during 2015 identified a considerable proportion (39\%) of secondary school boys (76.2\% were aged $15-17$ years) as ever smokers, which is higher than that in Qatar $(24.8 \%)^{26}$

Despite the fact that the age distribution among participants differed significantly between the three Surveys in Qatar $(p<0.001)$, the age of smoking initiation showed no significant difference over the years. Furthermore, the percentage of participants aged 13 years increased from $28.6 \%$ in 2004 , to $40.5 \%$ in 2007 , and $38.9 \%$ in 2013 . On the other hand, the proportion of respondents aged 15 years decreased from $31.7 \%$ in 2004 , to $24.6 \%$ in 2007 , and $23.9 \%$ in 2013 . In contrast, findings from 68 low- and middle-income countries showed that adolescents aged 14-15 years were more likely to smoke than those aged $12-13$ years $^{15}$.

Another major finding is the emboldened disbelief among school students regarding the harm of tobacco, which reached its peak in 2013 when almost a quarter $(23.1 \%)$ of the participants, up from $17.9 \%$ in 2007 , denied the harmful effects of tobacco use. Furthermore, smoking has become more socially acceptable, especially during gatherings. Similarly, almost half ( $52 \%)$ of the respondents in 2013 rejected the idea of banning tobacco use in enclosed public spaces. In addition, the aforementioned response revealed almost a triple increase compared to that of 2004 (15\%) and 2007 (19\%). Such findings could be explained by the increase in free tobacco promotion coupled with the significant decrease in the advertisement of antitobacco awareness messages in media, television, videos, movies, sports and community events from 2004 to 2013. Similarly, a previous study conducted among nationally representative samples of school students aged 13-15 years in GCC countries and Yemen showed that direct pro-tobacco advertising exposure was more than $70 \%$ in newspapers and on billboards ${ }^{13}$.

Furthermore, the analysis of the three GYTS surveys showed that there is an increasing trend in school education on the hazards of tobacco use by almost $28 \%$ from 2004 (18.7\%) to 2013 $(47.2 \%)$. Despite the fact that schools amplified the promotion of anti-tobacco health education, there was no change in the smoking beliefs and behavior among students. This finding indicates that a multidisciplinary approach involving the media, community and legislative authorities is needed in addition to health-promoting initiatives at the school level. Moreover, a study encompassing GYTS data from 43 countries conveyed that an increased awareness about the harm of tobacco among students was associated with the presence of tobacco prevention courses in their respective schools ${ }^{27}$. In addition, a review by Backinger et al. ${ }^{28}$ revealed that school curricula alone are ineffective in preventing youth smoking, unless coupled with other methods such as smoke-free policies ${ }^{28}$.

Our analysis also revealed an overall decrease in exposure to secondhand smoking at home and an increase in enclosed public spaces. The observed decline might indicate an increase in the level of awareness among the youth's family members; however, such issues need further assessment and control. Similarly, a study by Al-Zalabani et al. ${ }^{29}$ involving 3210 intermediate and secondary school students in Madinah, Saudi Arabia, showed that approximately one-third $(32.7 \%)$ were exposed to secondhand smoke at home. In addition to several health consequences of exposure, secondhand tobacco smoke is also known to be a predictor of future smoking initiation among the young especially if exposed at home ${ }^{30}$. Furthermore, Lessov-Schlaggar et al. ${ }^{31}$ identified sensitivity to secondhand smoke exposure among children 8-13 years old as one factor that heightens smoking susceptibility later in life ${ }^{31}$. 


\section{Limitations}

Some limitations should be considered when discussing the findings of this report. The use of a school-based survey might not be representative of all youths, especially those who dropped out of school. In addition, the data retrieved in the GYTS are based on self-reporting by students, who in turn might be prone to non-response bias resulting in over- or underestimation of the actual results. Another limitation of the study was that the data collected over the three years was cross-sectional and reflected different populations. As for the strengths, the study represents the first in Qatar where a weighting methodology was used to adjust for non-response.

\section{CONCLUSIONS}

Despite efforts made by the local authorities in Qatar to reverse the spread or limit the growing tobacco epidemic, there is still a need for multidisciplinary strategies to promote and enforce smoke-free policies vital to tobacco prevention and control programs targeting youths. In addition, the study findings provide information to help develop an adolescentspecific national tobacco control program, which will help combat this epidemic.

\section{REFERENCES}

1. Boston University Medical Center. The History of Tobacco. http://academic.udayton.edu/health/syllabi/ tobacco/history.htm\#begin. Accessed May 27, 2018.

2. World Health Organization. Tobacco. http://www.who. int/news-room/fact-sheets/detail/tobacco. Accessed May $27,2018$.

3. Mackay J, Eriksen M, Shafey O. The Tobacco Atlas. Atlanta, Georgia, USA: American Cancer Society; 2006.

4. American Cancer Society, Vital Strategies. The Tobacco Atlas. https://tobaccoatlas.org/. Accessed October 12, 2018.

5. World Health Organization. Adolescents: health risks and solutions. Available at: http://www.who.int/news-room/ fact-sheets/detail/adolescents-health-risks-and-solutions. Accessed May 27, 2018.

6. Mandil A, Chaaya M, Saab D. Health status, epidemiological profile and prospects: Eastern Mediterranean region. Int J Epidemiol. 2013;42(2):616-626. doi:10.1093/ije/dyt026

7. El-Awa F, Warren CW, Jones NR. Changes in tobacco use among 13-15-year-olds between 1999 and 2007: findings from the Eastern Mediterranean Region. East Mediterr Health J. 2010;16(3):266-273. doi:10.26719/2010.16.3.266

8. The Union. International Union Against Tuberculosis and Lung Disease: Eastern Mediterranean. Available at: https://www.tobaccofreeunion.org/index.php/where-wework/eastern-mediterranean/. Accessed May 27, 2018.

9. Voorhees CC, Ye C, Carter-Pokras O, et al. Peers, Tobacco Advertising, and Secondhand Smoke Exposure Influences Smoking Initiation in Diverse Adolescents. Am J Health Promot. 2011;25(3):e1-e11. doi:10.4278/ajhp.090604-QUAN-180

10. Thomas RE, McLellan J, Perera R. Effectiveness of schoolbased smoking prevention curricula: systematic review and meta-analysis. BMJ Open. 2015;5(3):e006976. doi:10.1136/bmjopen-2014-006976

11. Duncan LR, Pearson ES, Maddison R. Smoking prevention in children and adolescents: A systematic review of individualized interventions. Patient Educ Couns. 2018;101(3):375-388. doi:10.1016/j.pec.2017.09.011

12. Global Tobacco Surveillance System Collaborating Group. Global Tobacco Surveillance System (GTSS): purpose, production, and potential. J Sch Health. 2005;75(1):1524. doi:10.1111/j.1746-1561.2005.tb00004.x

13. Moh'd Al-Mulla A, Abdou Helmy S, Al-Lawati J, et al. Prevalence of Tobacco Use Among Students Aged 13-15 Years in Health Ministers' Council/Gulf Cooperation Council Member States, 2001-2004. J Sch Health. 2008;78(6):337343. doi:10.1111/j.1746-1561.2008.00311.x

14. World Health Organization, United Nations Development Programme. The WHO Framework Convention on Tobacco Control an Accelerator for Sustainable Development. https://www.who.int/fctc/ implementation/publications/who-fctc-undp-wntd-2017. pdf. Accessed May 27, 2018.

15. Xi B, Liang Y, Liu Y, et al. Tobacco use and secondhand smoke exposure in young adolescents aged 1215 years: data from 68 low-income and middle-income countries. Lancet Glob Health. 2016;11(4):e795-e805. doi:10.1016/s2214-109x(16)30187-5

16. Campaign for Tobacco-Free Kids. Tobacco Control Laws: Qatar. https://www.tobaccocontrollaws.org/legislation/ country/qatar/laws. Accessed May 27, 2018.

17. World Health Organization.Tobacco Free Initiative (TFI): Global youth tobacco survey (GYTS). http://www.who. int/tobacco/surveillance/gyts/en/. Accessed May 27, 2018.

18. Warren C, Jones N, Eriksen M, Asma S. Patterns of global tobacco use in young people and implications for future chronic disease burden in adults. The Lancet. 2006;367(9512):749-753. doi:10.1016/s0140-6736(06)68192-0

19. Warren CW, Jones NR, Peruga A, et al. Global youth tobacco surveillance, 2000-2007. MMWR Surveill Summ. 2008;57(1):1-28. https://www.cdc.gov/mmwr/preview/ mmwrhtml/ss5701a1.htm. Accessed October 12, 2018.

20. The Global Youth Tobacco Survey Collaborative Group. Tobacco use among youth: a cross country comparison. Tob Control. 2002;11(3):252-270. doi:10.1136/tc.11.3.252 
21. Tobacco Cessation Action Plan. http://studyres.com/ doc/15224435/tobacco-cessation-action-plan---2015. Accessed May 27, 2018.

22. Supreme Council of Health. Tobacco Cessation Action Plan. Doha: Supreme Council of Health; 2015.

23. Ribeiro Sarmento D, Yehadji D. An analysis of global youth tobacco survey for developing a comprehensive national smoking policy in Timor-Leste. BMC Public Health. 2016;16:65. doi:10.1186/s12889-016-2742-5

24. Roa R, Franklin-Peroune R, Jones NR, et al. Changes in tobacco use among youths aged 13-15 years - Panama, 2002 and 2008. MMWR. 2009;57(53):1416-1419. https://www.cdc.gov/mmwr/preview/mmwrhtml/ mm5753a4.htm. Accessed October 12, 2018.

25. Al Moamary MS, Al Ghobain MO, Al Shehri SN, Gasmelseed AY, Al-Hajjaj MS. Predicting tobacco use among high school students by using the global youth tobacco survey in Riyadh, Saudi Arabia. Ann Thorac Med. 2012;7(3):122-129. doi:10.4103/1817-1737.98843

26. Al Shemmari N, Shaikh RB, Sreedharan J. Prevalence of dokha use among secondary school students in Ajman, United Arab Emirates. Asian Pac J Cancer Prev. 2015;16(2):427-430. doi:10.7314/apjcp.2015.16.2.427

27. Agaku IT, Obadan EM, Odukoya OO, Olufajo O. Tobaccofree schools as a core component of youth tobacco prevention programs: a secondary analysis of data from 43 countries. Eur J Public Health. 2015;25(2):210-215. doi:10.1093/eurpub/cku203

28. Backinger CL, Fagan P, Matthews E, Grana R. Adolescent and young adult tobacco prevention and cessation: current status and future directions. Tob Control. 2003;12:iv46iv53. doi:10.1136/tc.12.suppl_4.iv46

29. Al-Zalabani AH, Amer SM, Kasim KA, Alqabshawi RI, Abdallah AR. Second-Hand Smoking among Intermediate and Secondary School Students in Madinah, Saudi Arabia. Biomed Res Int. 2015;2015:1-8. doi:10.1155/2015/672393

30. Gilman SE, Rende R, Boergers J, et al. Parental Smoking and Adolescent Smoking Initiation: An Intergenerational Perspective on Tobacco Control. Pediatrics. 2009;123(2):e274-e281. doi:10.1542/peds.2008-2251

31. Lessov-Schlaggar CN, Wahlgren DR, Liles S, et al. Sensitivity to Secondhand Smoke Exposure Predicts Future Smoking Susceptibility. Pediatrics. 2011;128(2):254-262. doi:10.1542/peds.2010-3156

\section{CONFLICTS OF INTEREST}

The authors have completed and submitted the ICMJE Form for Disclosure of Potential Conflicts of Interest and none was reported.

\section{FUNDING}

There was no source of funding for this research.

\section{AUTHORS' CONTRIBUTIONS}

Drafting of the work was by AAD. MEZ prepared the methodology section, performed the statistical analysis and wrote the results section. AAD, MAHC and $\mathrm{SN}$ contributed to the introduction, and to the interpretation and discussion of the findings. NAAS supervised all aspects of the manuscript. All authors participated in editing and correcting the final manuscript. All aspects of the final manuscript were approved by all authors.

PROVENANCE AND PEER REVIEW

Not commissioned; externally peer reviewed. 